\title{
Low-Frequency Volatility in China's Gold Futures Market and Its Macroeconomic Determinants
}

\author{
Song Liu, ${ }^{1}$ Tingfei Tang, ${ }^{1}$ Andrew M. McKenzie, ${ }^{2}$ and Yibin Liu ${ }^{3}$ \\ ${ }^{1}$ College of Economics and Management, South China Agricultural University, Guangzhou 510642, China \\ ${ }^{2}$ Department of Agricultural Economics and Agribusiness, University of Arkansas, Fayetteville, AR 72701, USA \\ ${ }^{3}$ Department of Economics, University of California, San Diego, CA 92093, USA \\ Correspondence should be addressed to Andrew M. McKenzie; mckenzie@uark.edu
}

Received 8 February 2015; Accepted 21 May 2015

Academic Editor: Reik Donner

Copyright (c) 2015 Song Liu et al. This is an open access article distributed under the Creative Commons Attribution License, which permits unrestricted use, distribution, and reproduction in any medium, provided the original work is properly cited.

\begin{abstract}
We extract low- and high-frequency volatility from China's Shanghai gold futures market using an asymmetric Spline-GARCH (ASP-GARCH) model. We then regress monthly low-frequency volatility on selected monthly macroeconomic indicators to study the impact of macroeconomy on gold futures market and to test for excess volatility. Our main result is volatility in China's Shanghai gold futures market resulting from both macroeconomic fluctuations and investor behaviour. Chinese Consumer Price Index Volatility and US dollar volatility are the two main determinants of low-frequency gold volatility. We also find significant evidence of excess volatility, which can in part be explained in terms of loss-aversive investor behaviour.
\end{abstract}

\section{Introduction}

The price of gold has undergone a series of drastic fluctuations since the 2008 global financial crisis. By September 2011, gold prices had climbed to an unprecedented high level of $\$ 1921$ per troy ounce from a level of $\$ 682$ per troy ounce in October 2008. However, gold prices quickly dropped by $\$ 400$ per troy ounce in merely 20 trading days following this historic peak. Since 2012 gold price volatility has continued unabated with many macroeconomic factors such as the global economic recovery and appreciating the US dollaraccording to analysts-potentially playing a driving role. However, extremely large gold price shocks such as a $14.8 \%$ decline that occurred over a three-day trading period in April 2013 have puzzled both academicians and industry analysts alike [1]. As a precious metal, gold is widely regarded as both a store of wealth and an inflation hedge and there is much interest in the investment community in determining if gold price volatility is simply excessive noise or is driven by sound macroeconomic fundamentals.

The Efficient Market Hypothesis (EMH) asserts that asset prices only respond to changes in fundamentals [2]. This has driven a large body of the literature to explore possible macroeconomic variables that can explain gold market volatility. For example, Wang et al. [3] found that the US dollar, crude oil prices, and global stock market performance had a significant impact on Shanghai's gold futures market. Tully and Lucey [4] similarly looked to macroeconomic effects to explain gold price shocks. They employed an asymmetric power GARCH model (APGARCH) to show that the US dollar is the main macroeconomic variable which influences gold. In contrast, Batten et al. [5] showed that gold price volatility responded primarily to monetary variables like M2 (broad money) and the inflation rate. In addition, Christie-David et al. [6] and Cai et al. [7] reported that announcements of macroeconomics news have a significant impact on gold prices.

The methodological approaches used in previous studies suffer from two noticeable flaws. First, prior research has utilized traditional GARCH-type models which set unconditional volatility as a constant and consequently are unlikely to capture the true dynamics of long-run market volatility. Long-run volatility is equivalent to low-frequency volatility which is assumed to be determined by slowly evolving macroeconomic variables, while high-frequency or short-run volatility is mainly attributed to noise.

Second, the observed frequency of macroeconomic variables does not synchronize with observed gold prices. 
Macroeconomic variables are generally compiled monthly or even quarterly while gold prices are reported daily or intradaily. Incorporating variables with different frequencies in the same model creates econometric modeling difficulties.

To address these issues, Engle and Rangel [8] and Rangel and Engle [9] developed Spline-GARCH and an asymmetric Spline-GARCH (ASP-GARCH) model which relax the assumption that unconditional volatility is constant. They use a quadratic spline to isolate the proportion of variation in daily price data that is plausibly caused by macroeconomic variables. Then, using the isolated variation, Engle and Rangel [8] construct a measure of low-frequency volatility in the same sampling frequency as macroeconomic data, which effectively bridges high-frequency commodity price with its low-frequency macroeconomic determinants. Karali and Power [10] followed Engle and Rangel [8] and decomposed daily price volatility into high- and low-frequency components. They found that low-frequency volatility in US gold futures market responds strongly to changes in the industrial production index, consumer price index, and the US dollar. However, to our knowledge, this modelling approach has not been used to study factors affecting volatility in China's gold futures market, which is the primary objective of this paper.

Although much research efforts have been devoted to studying the macroeconomic determinants of gold price volatility, it remains unclear whether these macroeconomic determinants sufficiently explain the high levels of observed gold market volatility. In this paper we examine whether Chinese gold futures market exhibits "excess volatility," a term first coined by LeRoy and Porter [11] and Shiller [12] and attributed to the portion of an asset's volatility that cannot be explained by fundamentals. Evidence of excess volatility poses a challenge to the Efficient Market Hypothesis $(\mathrm{EMH})$ - the cornerstone of traditional finance theoryfirst outlined in Malkiel and Fama [2]. A growing body of the literature spanning the last 40 years has accumulated significant empirical evidence of excess volatility in a variety of financial markets. For example, De Long and Becht [13] reported excess volatility in German stock market after the Second World War. Similarly, Campbell and Cochrane [14] showed that US stock market volatility is far greater than dividend volatility. This result indicates that, contrary to the $\mathrm{EMH}$, movements in dividends cannot be the sole determining factor of stock market volatility. There is also considerable evidence of excess volatility in Chinese stock and bond markets (e.g., [15-19]). Our paper extends this literature by shedding light on whether excess volatility is a prevalent feature of Chinese gold futures market.

The EMH and "Homo Economicus Assumption" fail to provide us with a widely accepted explanation of excess volatility in financial market. Proponents of behavioural finance would argue that classical theories fail because people are not rational in the classical economic sense. A number of studies grounded in behavioural finance theory-where market actors are assumed to be susceptible to cognitive biases-have been relatively successful in explaining excess volatility in stock markets. For example, investor sentiment has been shown to be a good explanation of excess volatility $[18,20-22]$. Drawing from Kahneman and Tversky's prospect theory, Barberis et al. [23] found that stock market investors are loss-aversive and their utility is affected by their previous investment returns. As a result, this form of loss aversion changes investors' required risk premium and hence impacts market volatility. In a similar vein, a recent study by Wang and Hua [24] found that volatility in China's copper futures markets correlates with investors' loss aversion, which supports the claim that investors' behaviour affects futures markets volatility.

In this paper we use an ASP-GARCH model to extract low-frequency volatility in China's gold futures market and its response to changes in macroeconomic variables. We find evidence of excess volatility in the market, which we explain in a behavioural framework following Barberis et al.'s [23] loss aversion modelling approach. Our main contributions are as follows: (1) we present the first empirical study to extract low-frequency volatility in China's gold futures market; (2) we are able to explain a portion of low-frequency volatility in terms of macroeconomic news; and (3) we find significant evidence of excess volatility in China's gold futures market, which we at least in part explain in terms of investor loss aversive behaviour.

\section{Modelling Approach and Hypotheses Testing}

2.1. ASP-GARCH Model. The assumption underlying almost all traditional GARCH models is that volatility is mean reverting to a constant level and unconditional volatility is constant. However, the mean reverting assumption has been greatly challenged by observation of real market movements. For example, it is widely recognized that volatility is higher during recessions and following "news" announcements [8]. Traditional GARCH model does not adequately capture the low-frequency changes in unconditional volatility whereas it is generally useful in modelling high-frequency conditional volatility. To address this issue Engle and Rangel [8] proposed a semiparametric Spline-GARCH model which relaxes the assumption that volatility is mean reverting to a constant level. To better understand how the Spline-GARCH model works, it is helpful for us to briefly review the traditional GARCH model. Bollerslev [25] proposed the GARCH model:

$$
\begin{aligned}
r_{t}-E_{t-1} r_{t} & =\sqrt{h_{t}} \varepsilon_{t}, \\
h_{t} & =\omega+\alpha \varepsilon_{t-1}^{2}+\beta h_{t-1}, \\
\varepsilon_{t} \mid I_{t-1} & \sim N(0,1),
\end{aligned}
$$

where $r_{t}$ is the investment return at time $t$, the expectation $E_{t-1}$ is conditional on an information set $I_{t-1}$ at time $t-1, \varepsilon_{t}$ is the innovation term assumed to be distributed with mean 0 and variance 1 , again conditioned upon the information set $I_{t-1}$ at time $t-1, h_{t}$ denotes the conditional variance of returns for period $t$, and $h_{t}$ is a function of past errors and squared errors and variances observed at time $t-1$. The terms $\omega, \alpha$, and $\beta$ are the estimated coefficients on these conditional variance $\mathrm{ARCH}$ and GARCH terms. Equation (1) is the mean equation and (2) is the conditional variance equation. 
Following Engle and Rangel [8], and focusing on the long-run properties of the model, the conditional variance equation can be rewritten in terms of the unconditional variance:

$$
h_{t}=\sigma^{2}+\alpha\left(\varepsilon_{t-1}^{2}-\sigma^{2}\right)+\beta\left(h_{t-1}-\sigma^{2}\right) \text {, }
$$

where $\sigma^{2}=\omega /(1-\alpha-\beta)$ is the unconditional variance. However, this model designed to capture conditional volatility fails to model long-term trends in unconditional volatility. When $\alpha+\beta<1$, the unconditional variance reverts to its mean value $\sigma^{2}$ at a geometric rate of $\alpha+\beta$. Therefore, as noted by Engle and Rangel [8], for a long horizon $T$, the $T$-days-ahead volatility forecast will be the same constant $\sigma$ no matter whether the forecast is made at day $t$ or at day $t-k, k>0$. To better study the dynamics of financial time series, a model that allows unconditional volatility $\sigma^{2}$ to vary slowly over time is much needed to capture the low-frequency component of volatility.

The Spline-GARCH model can decompose daily price volatility into high- and low-frequency components and thus is able to capture high-frequency news or noise component and also a low-frequency component incorporating market reactions to macroeconomic events:

$$
\begin{aligned}
& r_{t}=\sqrt{g_{t} \tau_{t}} \varepsilon_{t}, \\
& h_{t}=g_{t} \tau_{t}, \\
& g_{t}=(1-\alpha-\beta)+\alpha\left(\frac{r_{t-1}^{2}}{\tau_{t-1}}\right)+\beta g_{t-1}, \\
& \tau_{t}=c \exp \left(w_{0} t+\sum_{i=1}^{k} w_{i}\left(\left(t-t_{i-1}\right)_{+}\right)^{2}\right),
\end{aligned}
$$

where $r_{t}$ is a time series of zero-mean, white noise residuals from a conditional mean regression of asset prices. The term $g_{t}$ is the high-frequency component of the conditional variance while $\tau_{t}$ is the low-frequency component. $\varepsilon_{t}$ is distributed as i.i.d. normal $(0,1) . \alpha$ is the ARCH term; $\beta$ is the GARCH term. $\tau_{t}$ is the quadratic exponential time spline, $c$ is a constant, $w_{0} t$ is a time trend in the low-frequency volatility, $\sum_{i=1}^{k} w_{i}\left(\left(t-t_{i-1}\right)_{+}\right)^{2}$ is a low-order quadratic spline, and $\left(t-t_{i-1}\right)_{+}=\max \left(t-t_{i-1}, 0\right)$. The coefficients $w_{i}$ control the sharpness of the cycles described by the spline while the number of cycles is determined by the number of knots $k$, which divides the sample into $k$ equal parts: $1<t_{1}<$ $t_{2}<\cdots<t_{k}<t$. The number of cycles increases with $k$ and the duration of each cycle shortens as $k$ increases. The value of $k$ is selected based on a comparison of the Akaike Information Criterion for each specification. In the model, unconditional volatility is the same as low-frequency volatility: $E\left(r_{t}^{2}\right)=E\left(g_{t}\right) \tau_{t}=\tau_{t}$. The Spline-GARCH model uses an exponential quadratic spline to approximate the time-varying unconditional volatility by generating a smooth curve that describes the low-frequency component, which is likely to result from changes in macroeconomic variables. Equation (7) models the high-frequency volatility. Equation (8) nonparametrically estimates the low-frequency volatility.
Rangel and Engle [9] proposed the ASP-GARCH model which we apply in this paper and which extends the SplineGARCH model. In the ASP-GARCH model, the highfrequency component $g_{t}$ is different from its counterpart in Spline-GARCH model. Instead the $g_{t}$ component is modeled as in the GJR-GARCH model developed by Glosten et al. [26]:

$$
\begin{aligned}
g_{t}= & \left(1-\alpha-\beta-\frac{v}{2}\right)+\alpha\left(\frac{r_{t-1}^{2}}{\tau_{t-1}}\right)+v\left(\frac{r_{t-1}^{2}}{\tau_{t-1}}\right) I_{r_{t-1}<0} \\
& +\beta g_{t-1} .
\end{aligned}
$$

Equation (9) measures the leverage effect in high-frequency volatility, which is not feasible to estimate from (7). The leverage effect is observed when negative price shocks cause a larger change in volatility than do positive price shocks. $I_{r_{t-1}<0}$ is an indicator function of negative returns. If $v$ is significantly different from 0 , there is an asymmetric impact from prior positive versus negative price shocks on current volatility.

From (9), we obtain the high-frequency volatility in the gold futures market. From (8), we are able to extract the daily low-frequency volatility component $\tau_{t}$, which can be used to estimate $\tau_{t}\left(y_{t}\right)$, a volatility function explained by a subset of macroeconomic variables $y_{t}$. However, a problem with this approach is that macroeconomic data relevant to gold markets are observed monthly whereas we estimate low-frequency volatility from daily gold prices. Therefore, to proceed we need to construct a monthly low-frequency volatility series $\mathrm{LV}_{m}$ which can be matched seamlessly with macroeconomic variables:

$$
\mathrm{LV}_{m}=\sqrt{\frac{1}{N_{m}} \sum_{d=1}^{N_{m}} \tau_{d, m}}
$$

where $\tau_{d, m}$ is the low-frequency volatility of month $m$ and day d. $N_{m}$ is the number of trading days in month $m$.

For any given $k$, we can estimate the Spline-GARCH model which follows a normal distribution by maximum likelihood estimation. The log likelihood function is given as

$$
L=-\frac{1}{2} \sum_{t=1}^{T}\left(\log \left(\tau_{t} g_{t}\right)+\frac{r_{t}^{2}}{\tau_{t} g_{t}}\right)
$$

Once we have monthly low-frequency volatility data for China's gold futures market, we can proceed to test the impact of macroeconomic indicators on our low-frequency volatility series. Specifically, we estimate the following multivariable linear regression where low-frequency volatility is the dependent variable and relevant macroeconomic variables are independent variables:

$$
\begin{aligned}
\mathrm{LV}_{m}= & a+\sum_{i=1}^{n} b_{i} z_{i, m}+v_{1} \mathrm{DF}_{m}+v_{2} \mathrm{DW}_{m}+v_{3} \mathrm{DS}_{m} \\
& +e_{k, m}
\end{aligned}
$$

where $\mathrm{LV}_{m}$ is the low-frequency volatility in the gold futures market, $z_{i, m}$ is the volatility of macroeconomic variable $i$ in month $m$ (the specific macroeconomic variables considered 
in the study are explained in Section 3), and $e_{k, m}$ is the residual term. To account for seasonality, $\mathrm{DF}_{m}, \mathrm{DW}_{m}$, and $\mathrm{DS}_{m}$ are binary dummy variables for fall, winter, and spring, respectively. For example, $\mathrm{DF}_{m}$ takes a value of one if $m$ is September, October, or November and zero otherwise. $\mathrm{DW}_{m}$ takes a value of one if $m$ is December, January, or February and zero otherwise. $\mathrm{DS}_{m}$ takes a value of one if $m$ is March, April, or May and zero otherwise. $a$ is a constant that captures low-frequency volatility in summer months; $b_{i}$ is the coefficient with respect to the macroeconomic variable $i$. $v_{1}, v_{2}$, and $v_{3}$ are the coefficients that measure seasonality. Although we believe that (12) provides an adequate measure of the influence of our chosen macroeconomic variables on low-frequency gold volatility, it should be noted that we did not conduct an extensive analysis to determine potential correlations between macroeconomic variables.

2.2. Hypotheses Testing. Following Engle and Rangel [8] and Rangel and Engle [9], we assume that low-frequency volatility is largely caused by changes in fundamentals while highfrequency volatility is largely driven by noise. So, one measure of "excess volatility" is the ratio of low-frequency volatility to total volatility in a market:

$$
C=\frac{\operatorname{Var}\left[\log \left(\tau_{t}\right)\right]}{\operatorname{Var}\left[\log \left(g_{t} \tau_{t}\right)\right]},
$$

where $C$ is the ratio of low-frequency volatility to total volatility. If $C<1$, total volatility is greater than the volatility caused by fluctuations in fundamentals, supporting the existence of excess volatility in the market. Of course this is a somewhat crude measure as some high-frequency volatility is probably driven by short-term "news" relevant to gold market fundamentals.

Our empirical results, presented in Section 3, show strong evidence of excess volatility in Chinese gold futures marketin the sense that high-frequency volatility comprises a much larger component of total volatility than low-frequency volatility. This result begs the question what is the cause of such "excess volatility"? We turn to behavioural finance theory to answer this question and follow Barberis et al. [23] and test for the impact of investor loss aversion on excess volatility in China's gold futures market. Under this approach we assume that $z_{t}$ represents the previous day's modified investment return for a long futures position. Note that we assume that long-futures traders-who will profit from an increase in gold prices-are likely to be more susceptible to "loss aversion" than short-futures traders, who profit from short-term falls in gold prices. This assumption is consistent with the notion that institutional trading firms wishing to capture returns associated with rising gold prices, and who take a long-term investment position in gold, incorporate long gold futures positions in their investment portfolios to replicate cash gold. Irwin and Sanders [27] note that investors can gain exposure to commodity price increases through commodity index funds that hold long commodity futures positions. As such, these firms (long-futures traders) are akin to traditional stock market investors and are particularly sensitive to investment losses. However, our modelling approach is able to discern if short-futures trader "loss aversion" also contributes to gold price volatility. The return is modified in the sense that it is compared with an historical benchmark return for the market to incorporate a behavioural framing effect, which is assumed to influence investor behaviour. It is formally defined as $z_{t}=\psi_{t} / S_{t}$, where $\psi_{t}$ is the historical benchmark price of gold while $S_{t}$ is the current price of gold at time $t$. $z_{t}$ depends on the historical performance of gold prices and can be either $>1$ (when $\psi_{t}>S_{t}$ and there is previous investment loss), $<1$ (when $\psi_{t}<S_{t}$ and there is previous investment gain), or $=1$ (when $\psi_{t}=S_{t}$ ). $\psi_{t}$ varies with current gold price but at a lower rate. Equation (14) models the dynamics of $z_{t}$ :

$$
z_{t+1}=\eta\left(z_{t} \frac{\bar{R}}{R_{t+1}}\right)+(1-\eta) \quad \eta \in(0,1),
$$

where $\bar{R}$ is a fixed parameter which sets the median of $z_{t}$ over the time period of our data set to 1 . In other words, the chance of investment loss or gain over our data set is $50-50 . \bar{R}$ is average return; $R_{t+1}$ is the return at time $t+1$. If there is an investment gain, $R_{t+1}>\bar{R}$, and $z$ declines; conversely if there is an investment loss, then $R_{t+1}<\bar{R}$, and $z$ increases. The term $\eta$ measures investor's memory. The closer $\eta$ is to 0 , the closer $\psi_{t}$ is to the current price of gold $S_{t}$. This is indicative of the case when investors have a short memory and they are generally not influenced by previous gain or loss. However, when $\eta$ is closer to $1, \psi_{t}$ moves slowly and investors have a long memory of their investment performance.

To assess the impact of long-futures investor loss aversion on high-frequency volatility we regress

$$
g_{t}=c+v_{1} z_{t-1}^{\prime} I_{t-1}^{+}+v_{2} z_{t-1}^{\prime} I_{t-1}^{-}+\varepsilon_{t}
$$

where $g_{t}$ is the high-frequency component of the volatility in China's gold futures market that we estimate from (9). $z_{t}^{\prime}$ is the modified-taking account of the historical benchmark price of gold-daily log return of a long-futures gold investment at time $t$. If $z_{t}^{\prime}$ is positive (indicating a modified investment loss), $I^{+}$takes the value of 1 and otherwise takes the value 0 ; if $z_{t}^{\prime}$ is negative (indicating a modified investment gain), then $I^{-}$ takes the value of 1 and takes the value 0 otherwise. If $v_{1}$ and $v_{2}$ are statistically significant, both previous gains and losses to a long-futures position cause high-frequency volatilitywhich we associate with excess volatility-in China's gold futures market. If $v_{1}>0$, prior loss intensifies volatility. If $v_{2}<0$, prior gain increases volatility. Note that a prior loss from the perspective of a long-futures trader is equivalent to a prior gain of the same magnitude from the perspective of a short-futures trader and vice versa. By further comparing the absolute values of $v_{1}$ and $v_{2}$, we are able to determine the asymmetric impact of previous investment gain/loss to a long-futures position on excess volatility in China's gold futures market.

\section{Empirical Analysis}

3.1. Extracting Low-Frequency Volatility. First, we construct monthly low-frequency volatility using daily gold futures 


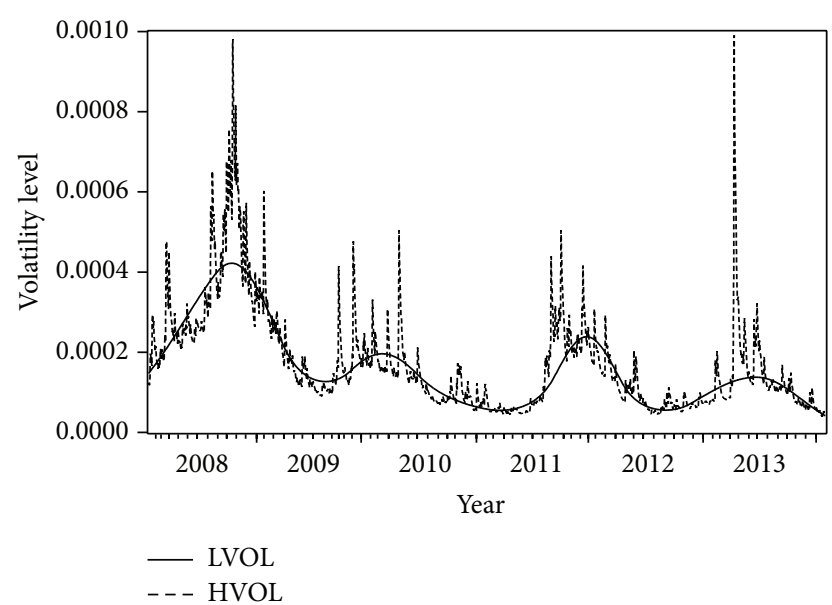

FIGURE 1: High- and low-frequency volatility in China's gold futures market. Note. LVOL is low-frequency volatility while HVOL means high-frequency volatility.

price data. We use daily settlement price of the main contract in Shanghai's gold futures market ranging from January 9, 2008, to December 31, 2013. In total, there are 1423 data points. The source of the data is Resset Financial Database (http://www.resset.cn/cn/). To ensure stationarity, we use the log return of gold futures:

$$
R_{t}=100 \times \ln \left(\frac{P_{t}}{P_{t-1}}\right)
$$

where $R_{t}$ is the $\log$ return at time $t$ and $P_{t}$ is the daily settlement price at time $t$.

We obtain a white noise residual series $r_{t}$ from regressing $R_{t}$ on its unconditional mean as in the following equation:

$$
R_{t}=\mu+r_{t} .
$$

We then apply the ASP-GARCH model ((5), (6), (8), and (9)) to the series $r_{t}$ and report the results in Table 1 . As noted, most of the coefficients are statistically significant at $5 \%$ level. We base our selection of the number of knots by AIC and the optimal number of knots is 10 . Hence, there are 10 cycles in low-frequency volatility in China's gold futures market from 2008 to 2013. Given our relatively small timeframe we assume that the cycles are of equal length, which is consistent with Karali and Power [10] who found 8 cycles of equal length for gold over the 2006-09 period. Figure 1 charts both high- and low-frequency volatility in China's gold futures market. It is obvious from Figure 1 that gold futures price is most volatile in October 2008, March 2010, December 2011, and June 2013. Out of these 4 time periods, October 2008, which is at the height of global financial crisis, witnessed the most volatile gold futures price. Our ASP-GARCH volatility estimates are consistent with observed volatility in the market, and insample model predictions capture the unprecedented price spikes.

3.2. Macroeconomic Determinants of Low-Frequency Volatility. Now that low-frequency volatility has been estimated
TABLE 1: Estimates from ASP-GARCH model in China's gold futures market.

\begin{tabular}{lcc}
\hline & Coefficients & SE \\
\hline$\alpha$ & $0.0774^{* * *}$ & 0.0212 \\
$\beta$ & $0.7908^{* * *}$ & 0.0436 \\
$c$ & $1.4448 e-004^{* * *}$ & $5.1803 e-005$ \\
$w_{0}$ & $0.0103^{* * *}$ & $2.8767 e-003$ \\
$w_{1}$ & $-2.2463 e-005^{* * *}$ & $4.4678 e-006$ \\
$w_{2}$ & $-3.4088 e-005^{* * *}$ & $3.1679 e-006$ \\
$w_{3}$ & $1.2517 e-004^{* * *}$ & $7.4997 e-006$ \\
$w_{4}$ & $-1.2422 e-004^{* * *}$ & $6.9961 e-006$ \\
$w_{5}$ & $7.1531 e-005^{* * *}$ & $1.1471 e-005$ \\
$w_{6}$ & $5.4542 e-005^{* * *}$ & $1.9246 e-005$ \\
$w_{7}$ & $-1.8847 e-004^{* * *}$ & $3.5234 e-005$ \\
$w_{8}$ & $2.1296 e-004^{* * *}$ & $4.7238 e-005$ \\
$w_{9}$ & $-1.2909 e-004^{* *}$ & $5.6524 e-005$ \\
$w_{10}$ & $-2.3390 e-005$ & $8.2915 e-005$ \\
$v$ & 0.0227 & 0.0294 \\
Log likelihood & 5594.1610 & \\
AIC & -7.8510 & \\
\hline
\end{tabular}

Note. $* * *, * *$ denote significance at the $1 \%$ and $5 \%$ levels, respectively. SE is the covariance based standard error of estimated coefficients.

from the ASP-GARCH model, we proceed with estimating the impact that macroeconomic variables may have on lowfrequency volatility. To bridge daily low-frequency volatility data with monthly macroeconomic indicators, we use (10) to construct monthly low-frequency volatility series $L_{m}$ which is in turn regressed upon macroeconomic and seasonal dummy variables as in (12).

Gold price is influenced by both supply and demand and macroeconomic conditions. Potential macroeconomic variables include, but are not limited to, Gross Domestic Product (GDP), inflation rate, United States dollar USD exchange rate, interest rate, $\mathrm{M} 2$, unemployment rate, oil price, stock indices, prices of substitutes (e.g., silver), and political risk. We exclude GDP from our study since GDP is reported quarterly and consequently we are only able to obtain 24 data points of GDP from 2008 to 2013. Instead, we use Consumer Confidence Index and Industrial Production (both compiled monthly) as proxies for GDP. Industrial Production is an important economic indicator of production and industry; the Consumer Confidence Index (CCI) is a compound index which incorporates information on employment, income, price, interest rate, and so forth, and reflects people's confidence in and expectation of the economy. It is worth noting that the unemployment rate in China is reported quarterly and so again we choose to omit this variable from our analysis. Nevertheless, we believe that CCI is a plausible proxy for unemployment rate since CCI takes into account people's employment as well. Lastly, we exclude political risk from the regression since it is extremely difficult to quantify.

To sum up, we choose the following monthly Chinese macroeconomic variables based upon relevance and availability: Chinese Consumer Price Index Volatility (CPIVOL), Chinese Industrial Production Volatility (IPVOL), Chinese 
TABLE 2: Estimates from regression of low-frequency volatility in China's gold futures market on volatility of macroeconomic variables.

\begin{tabular}{|c|c|c|c|c|c|}
\hline \multicolumn{3}{|c|}{ Regression on Chinese macroeconomic volatility variables } & \multicolumn{3}{|c|}{ Regression on US macroeconomic volatility variables } \\
\hline Variable & Coefficients & SE & Variable & Coefficients & SE \\
\hline CPIVOL & $4.053267^{* * *}$ & 0.497055 & CPIVOL & $3.481405^{* * *}$ & 0.508096 \\
\hline IPVOL & -0.000414 & 0.000596 & IPVOL & $9.10 \mathrm{E}-06^{*}$ & $5.34 E-06$ \\
\hline IRVOL & $2.32 E-05$ & $1.78 E-05$ & IRVOL & $-0.000141^{*}$ & $7.21 E-05$ \\
\hline FXVOL & $0.105768^{* * *}$ & 0.039564 & FXVOL & $0.126571^{* * *}$ & 0.043275 \\
\hline M2VOL & 0.118330 & 0.111885 & M2VOL & $5.52 \mathrm{E}-05^{*}$ & $3.09 E-05$ \\
\hline CCIVOL & -0.100860 & 0.352567 & CCIVOL & 1.040476 & 2.065703 \\
\hline Intercept & $-4.78 E-05$ & $3.47 E-05$ & Intercept & $-1.93 E-05$ & $2.63 E-05$ \\
\hline Spring & $2.37 E-05$ & $2.20 E-05$ & Spring & $1.83 E-05$ & $1.96 E-05$ \\
\hline Winter & $2.68 E-05$ & $2.15 E-05$ & Winter & $1.32 E-06$ & $1.93 E-05$ \\
\hline Fall & $9.58 E-06$ & $2.12 E-05$ & Fall & $-8.97 E-06$ & $1.95 E-05$ \\
\hline Adjusted $R^{2}$ & 0.626325 & & Adjusted $R^{2}$ & 0.655592 & \\
\hline$F$-statistic & $13.850280^{* * *}$ & & $F$-statistic & $16.016770^{* * *}$ & \\
\hline
\end{tabular}

Note. The left panel of the table presents results of regression of low-frequency Chinese gold volatility on volatility of Chinese macroeconomic variables; the right panel presents results of regression of low-frequency Chinese gold volatility on volatility of US macroeconomic variables (except for CPIVOL). SE is the covariance based standard error of estimated coefficients.

$* * *$ and $*$ denote significance at the $1 \%$ and $10 \%$ levels, respectively.

Interbank Lending Rate Volatility (IRVOL), US Dollar Foreign Exchange Rate Index Volatility (FXVOL), Chinese Money Supply Volatility (M2VOL), and Chinese Consumer Confidence Volatility (CCIVOL). These monthly volatilities are estimated over the January 2008 to December 2013 period yielding 72 observations for each series. The source is Zhongjinwang Statistical Database (http://db.cei.gov.cn/ page/Default.aspx) and Economy Prediction System (EPS) Statistical Database (http://www.epsnet.com.cn/).

The estimates of (12) are reported in Table 2. The left half of Table 2 reports the results of the regression of lowfrequency Chinese gold market volatility on the volatility of Chinese macroeconomic variables, while the right half of Table 2 provides a comparison regression of low-frequency Chinese gold market volatility on volatility of comparable US macroeconomic variables. Given the global influence of the US economy, we wanted to test whether the same set of macroeconomic variables from the US are able to explain the low-frequency volatility in China's gold futures market. Thus, to specify (12) in terms of US macroeconomic variable volatilities, we simply replace all of our Chinese macroeconomic volatility variables-except for the Chinese Consumer Price Index Volatility (CPIVOL) - with variables from the US. We relabel our US variable volatilities as US Industrial Production Volatility (USIPVOL), US Interbank Lending Rate Volatility (USIRVOL), US Money Supply Volatility (USM2VOL), and US Consumer Confidence Volatility (USCCIVOL). First, with respect to our Chinese macroeconomic results, the coefficients of CPIVOL and FXVOL are positive and statistically significant at $1 \%$ level. However, all other coefficients are insignificant. Also, we find no evidence of seasonality in China's gold futures market. Our macroeconomic variables explain $63 \%$ of variation in low-frequency Chinese gold market volatility. In sum, lowfrequency volatility in China's gold futures market is mainly driven by volatility in CPIVOL and FXVOL. This may be explained by the fact that gold is commonly used by investors as an inflation hedge. Specifically, investors' demand for gold is higher when they expect higher inflation in the future and this in turn results in higher levels of low-frequency gold market volatility. Moreover, gold price is quoted and traded in US dollars. Generally speaking, gold price rises when the US dollar weakens. This explains why low-frequency volatility of gold covaries closely with volatility in the US dollar. Based on our findings, CPIVOL and the US dollar can be used as signals of the potential risk in gold futures market. Investors in China's gold futures market should pay close attention to movements in CPIVOL and the US dollar.

Turning to our US macroeconomic results presented in the right half of Table 2, we again find that volatility coefficients with respect to CPIVOL and FXVOL are again statistically significant at $99 \%$ confidence level-consistent with our Chinese macroeconomic variable specification. However, other US macroeconomic variables-with the exception of CCIVOL-are also statistically significant at $90 \%$ confidence level. We find that an increase in US interest rate volatility slightly lowers the low-frequency volatility in China's gold futures market. In addition, an increase in Industrial Production and M2 volatility in the US increases low-frequency volatility in China's gold futures market by a small amount.

Combining the results from both regressions, our preliminary finding is that industrial production and monetary policy in the US have an impact on China's gold futures market by affecting its low-frequency volatility. Conversely, there is no evidence that China's own industrial output and monetary policy directly influence its own gold futures market. A plausible explanation is that gold price is largely affected by the US dollar which is determined mainly by US Federal Reserve's monetary policies. Industrial Production is a key signal of the macrotrend in industrial output 
and economic development. In addition, we would argue that economic conditions may affect the demand for gold through people's expectation about future economic growth and wealth. Therefore, it is not surprising that Industrial Production in the US could affect low-frequency volatility in China's gold futures market.

However, an interesting question arising from our results is why is there no evidence of China's Industrial Production affecting China's gold market? One possible explanation could be that US (international) gold market volatility spillovers dominate China's gold futures market. Along these lines because of the dominant role played by the US in global financial markets, US macroeconomic variables are closely watched by gold traders all over the world. It is plausible that Chinese investors in Chinese gold futures market also look to the US economy when making their trading/investment decisions.

\subsection{Testing Excess Volatility in China's Gold Futures Mar-} ket. Our regression results show that the variance of lowfrequency volatility is largely explained by the selected macroeconomic variables. This finding lends support to the claim that low-frequency volatility mirrors changes in macroeconomic fundamentals. However, the question remains as to whether changes in macroeconomic fundamentals associated with low-frequency volatility explain total gold market volatility. Recall that if high-frequency volatility dominates low-frequency volatility, then this would suggest that Chinese gold futures market exhibits "excess volatility" the component of overall volatility that cannot be explained by fundamentals. Of course, we acknowledge that our linear regression model is likely not a complete description of all market fundamentals pertinent to the gold market. With this in mind we turn to our "excess volatility" results.

We estimate $C$ from (13)-the ratio of low-frequency volatility to total volatility-to be 0.7802 . This shows that macroeconomic fundamentals account for $78.02 \%$ of the overall volatility in China's gold futures market. This, in turn, illustrates that there is a considerable proportion of volatility that is not due to changes in fundamentals, a key signal of excess volatility.

We also calculate the same $C$ ratio with respect to London's gold market. In this case we find that fundamental driven low-frequency volatility accounts for $93 \%$ of overall volatility, considerably higher than its Chinese counterpart. We tentatively conjecture that there are probably higher levels of short-term speculation and irrationality-in the classical EMH sense-among traders in China's gold futures given that London is a more mature/developed market. However, it is important to qualify our results by acknowledging that not all influences on traders' activities (e.g., political risk) can be reasonably quantified. We surmise that behavioural factors may play an important role in determining volatility in China's gold market-a hypothesis that we turn to in the next section.

3.4. Behavioural Explanation of Excess Volatility. Following Barberis et al. [23], we set $\eta$ in (14) to 0.9 and estimate a modified long-futures returns time series $z$, which measures
TABLE 3: Asymmetric impact of investment gain/loss on excessive volatility in China's gold futures market.

\begin{tabular}{lcccc}
\hline Variable & Coefficients & SE & $t$-statistics & $p$ value \\
\hline$c$ & 0.88472 & 0.016013 & 55.24815 & 0.0000 \\
$v_{1}$ & 31.02509 & 1.491269 & 20.80448 & 0.0000 \\
$v_{2}$ & -17.62709 & 1.840754 & -9.57601 & 0.0000 \\
Adjusted $R^{2}$ & 0.23440 & & $F$-statistic & $218.3726^{* * *}$ \\
\hline
\end{tabular}

Note. $* * *$ denotes significance at the $1 \%$ level. SE is standard error of estimated coefficients.

the investment gain or loss against a historical benchmark. We then regress the high-frequency volatility component $g_{t}$ on $z$ using the specification in (15).

Our results are reported in Table 3. As seen from Table 3, all the parameters are statistically significant at $1 \%$ level. We find that both $v_{1}$ and $v_{2}$ are significant, showing that excess volatility in the market results from prior gains and losses to a long-futures position. Given the nature of futures markets an alternative way of looking at this is to say that prior losses to both long- and short-futures positions impact gold futures volatility. However, our Wald's test results indicate that there is an asymmetric impact with prior losses to long-futures positions having a larger effect on excess gold volatility than prior losses to short-futures positions $\left|v_{1}\right|>\left|v_{2}\right|$. This is consistent with our assumption that long-futures traders (predominantly long-term institutional investment firms) are more sensitive to losses than short-traders. According to our results investors' prior investment return is able to explain $23.4 \%$ of the variance in excess volatility (adjusted $R$-square reported in Table 3).

\section{Conclusions}

This study uses the ASP-GARCH model to extract both low- and high-frequency volatility from China's gold futures market. Our low-frequency volatility measures are regressed on a list of selected macroeconomic variables to determine the extent to which the market follows "traditional" rational economic theory. We also test for and find significant evidence of excess volatility in the market which we explain in the light of behavioural finance theory.

Our main conclusions can be summarized as follows. First, we find excess volatility in China's gold futures market, which cannot purely be explained in terms of market fundamentals. In comparison to London's long established gold market, China's gold futures market is more susceptible to speculation.

Second, loss aversion is an important factor contributing to excess volatility. Investors' prior investment performance leads to changes in the degree of loss aversion which exerts a great impact on investors' following decisions. Moreover, investment loss from the perspective of a long futures trader has a greater impact on excess volatility than does investment gain.

Third, volatility in China's gold futures market results from both fundamentals and short-term speculative behaviour. With respect to fundamentals, China's domestic 
Consumer Price Index Volatility (CPIVOL) and US dollar volatility are the major movers of the gold market, whereas China's Industrial Production, interest rate, and M2 volatilities do not have a significant impact. We also find that US Industrial Production, interest rates, and M2 volatilities are significant factors in explaining volatility in China's gold futures market. We argue that such a phenomenon implies that Chinese gold futures price movements are influenced by the changes in US fundamentals. On a final note, we acknowledge that likely covariance between the macroeconomic variables qualifies the extent to which each variable should be considered as truly independent drivers of Chinese gold futures volatility.

\section{Conflict of Interests}

The authors declare that there is no conflict of interests regarding the publication of this paper.

\section{Acknowledgment}

This research is supported by China Scholarship Foundation (201208440325).

\section{References}

[1] J. Farchy and D. McCrum, "Gold hit by sharpest tumble in 30 years," Financial Times, 2013.

[2] B. G. Malkiel and E. F. Fama, "Efficient capital markets: a review of theory and empirical work," The Journal of Finance, vol. 25, pp. 383-417, 1970.

[3] W. Wang, H. Bu, and F. Lu, "An empirical study on volatility in China's gold futures market under financial crisis," Management Review, vol. 2, pp. 77-83, 2009.

[4] E. Tully and B. M. Lucey, "A power GARCH examination of the gold market," Research in International Business and Finance, vol. 21, no. 2, pp. 316-325, 2007.

[5] J. A. Batten, C. Ciner, and B. M. Lucey, "The macroeconomic determinants of volatility in precious metals markets," Resources Policy, vol. 35, no. 2, pp. 65-71, 2010.

[6] R. Christie-David, M. Chaudhry, and T. Koch, "Do macroeconomic news releases affect gold and silver prices," Journal of Economics and Business, vol. 52, pp. 405-421, 2000.

[7] J. Cai, Y.-L. Cheung, and M. C. S. Wong, "What moves the gold market?" Journal of Futures Markets, vol. 21, no. 3, pp. 257-278, 2001.

[8] R. F. Engle and J. G. Rangel, "The spline-GARCH model for low-frequency volatility and its global macroeconomic causes," Review of Financial Studies, vol. 21, no. 3, pp. 1187-1222, 2008.

[9] J. G. Rangel and R. F. Engle, “The factor-spline-GARCH model for high and low frequency correlations," Journal of Business \& Economic Statistics, vol. 30, no. 1, pp. 109-124, 2012.

[10] B. Karali and G. J. Power, "Short- and long-run determinants of commodity price volatility," American Journal of Agricultural Economics, vol. 95, no. 3, pp. 724-738, 2013.

[11] S. F. LeRoy and R. D. Porter, "The present-value relation: tests based on implied variance bounds," Econometrica, vol. 49, no. 3, pp. 555-574, 1981.
[12] R. J. Shiller, "Do stock prices move too much to be justified by subsequent changes in dividends?" The American Economic Review, vol. 71, no. 3, pp. 421-436, 1981.

[13] J. B. De Long and M. Becht, "Excess volatility and the German stock market, 1876-1990," NBER Working Papers no. 4054, National Bureau of Economic Research, 1992.

[14] J. Y. Campbell and J. H. Cochrane, "By force of habit: a consumption-based explanation of aggregate stock market behavior," Journal of Political Economy, vol. 107, no. 2, pp. 205251, 1999.

[15] J. He and Y. Huo, "Investor behavior, asset price and stock market volatility," Nankai Economic Studies, vol. 2, pp. 62-67, 2004.

[16] C. Xu and H. Song, "Excess volatility in China's closed-end funds," Economic Research Journal, vol. 3, pp. 33-44, 2005.

[17] J. Xu, "Excess volatility in China's stock-a market," Journal of Financial Research, vol. 8, pp. 94-111, 2010.

[18] H. Zhou, W. Wu, and Y. Zhou, "Investor sentiment and volatility in China's stock market," Shanghai Economic Review, vol. 4, pp. 3-13, 2012.

[19] J. Bao and J. Pan, "Bond illiquidity and excess volatility," Review of Financial Studies, vol. 26, no. 12, pp. 3068-3103, 2013.

[20] W. F. de Bondt and R. Thaler, "Does the stock market overreact?” The Journal of Finance, vol. 40, no. 3, pp. 793-805, 1985.

[21] J. Pontiff, "Excess volatility and closed-end funds," The American Economic Review, vol. 87, no. 1, pp. 155-169, 1997.

[22] S. Lin and Q. Yu, "Limited rationality, animal spirit and market collapse: an experimental study on investor sentiment and trading behavior," Economic Research Journal, vol. 8, pp. 115-127, 2010.

[23] N. Barberis, M. Huang, and T. Santos, "Prospect theory and asset prices," Quarterly Journal of Economics, vol. 116, no. 1, pp. $1-53,2001$.

[24] Y. Wang and R. Hua, "Investor behavior and futures market volatility based on OLG model and high-frequency data," Chinese Journal of Management Science, vol. 1, pp. 91-101, 2012.

[25] T. Bollerslev, "Generalized autoregressive conditional heteroskedasticity," Journal of Econometrics, vol. 31, no. 3, pp. 307327, 1986.

[26] L. R. Glosten, R. Jagannathan, and D. E. Runkle, “On the relation between the expected value and the volatility of the nominal excess return on stocks," The Journal of Finance, vol. 48, no. 5, pp. 1779-1801, 1993.

[27] S. H. Irwin and D. R. Sanders, "Index funds, financialization, and commodity futures markets," Applied Economic Perspectives and Policy, vol. 33, no. 1, pp. 1-31, 2011. 


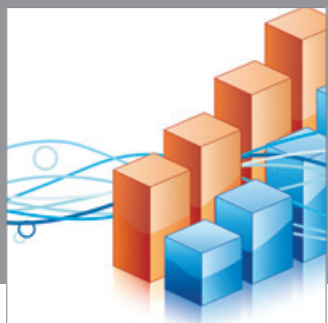

Advances in

Operations Research

mansans

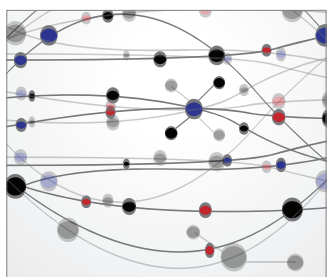

The Scientific World Journal
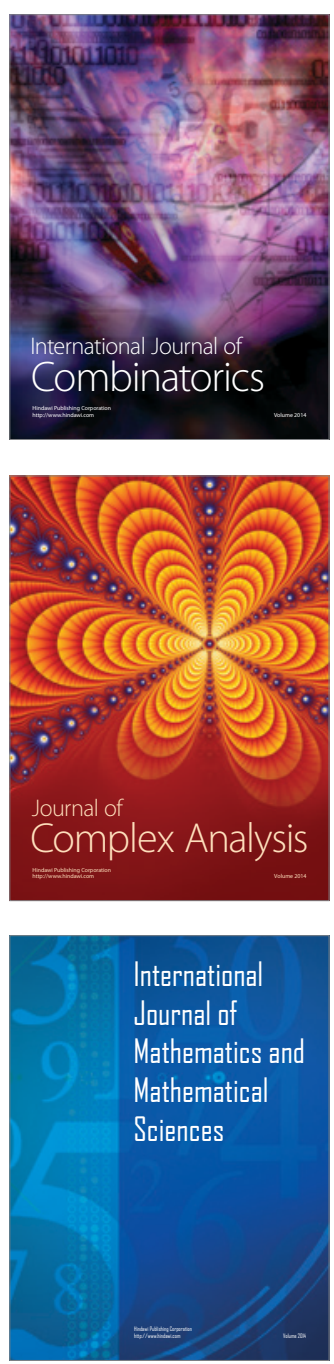
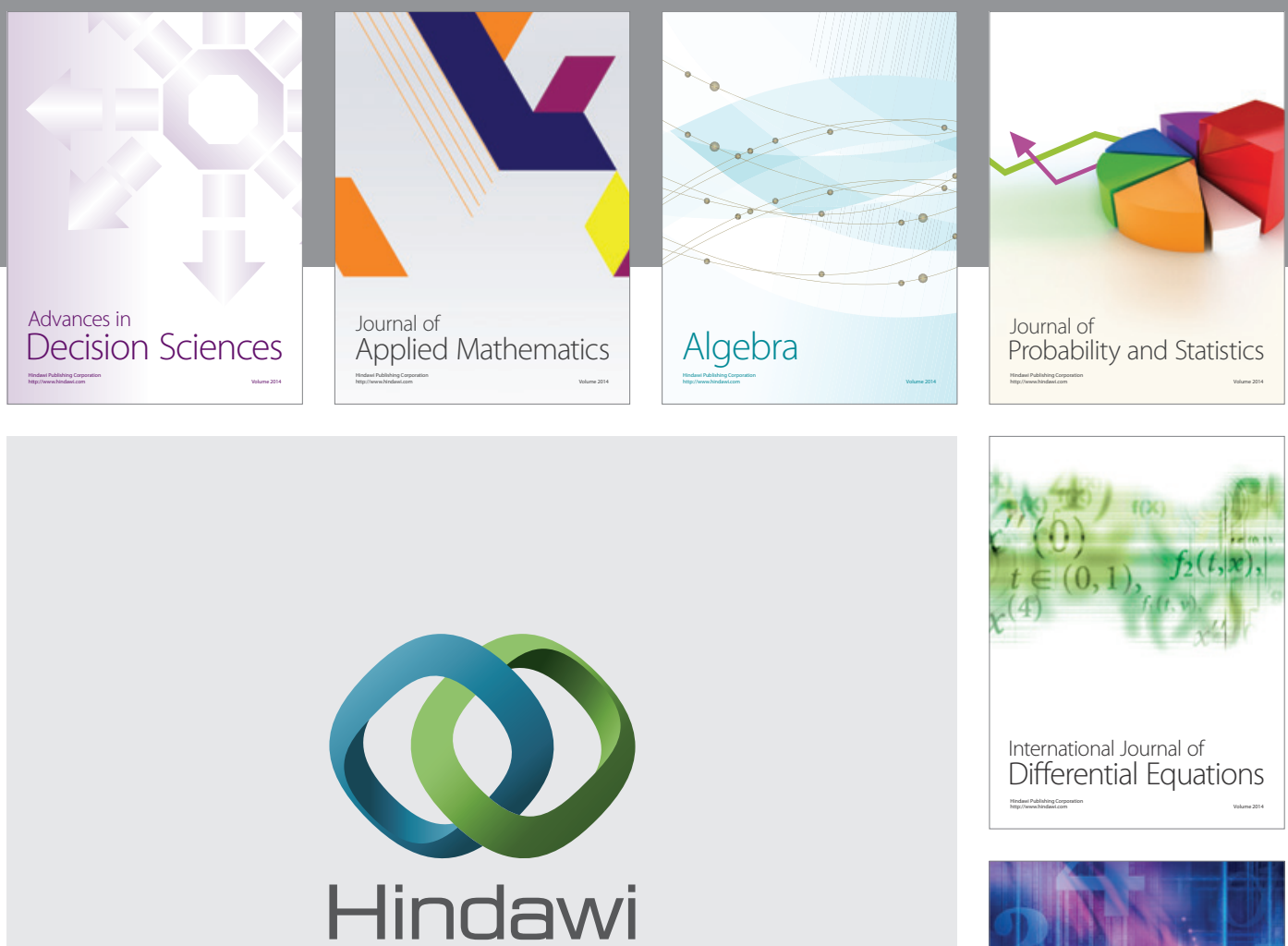

Submit your manuscripts at http://www.hindawi.com
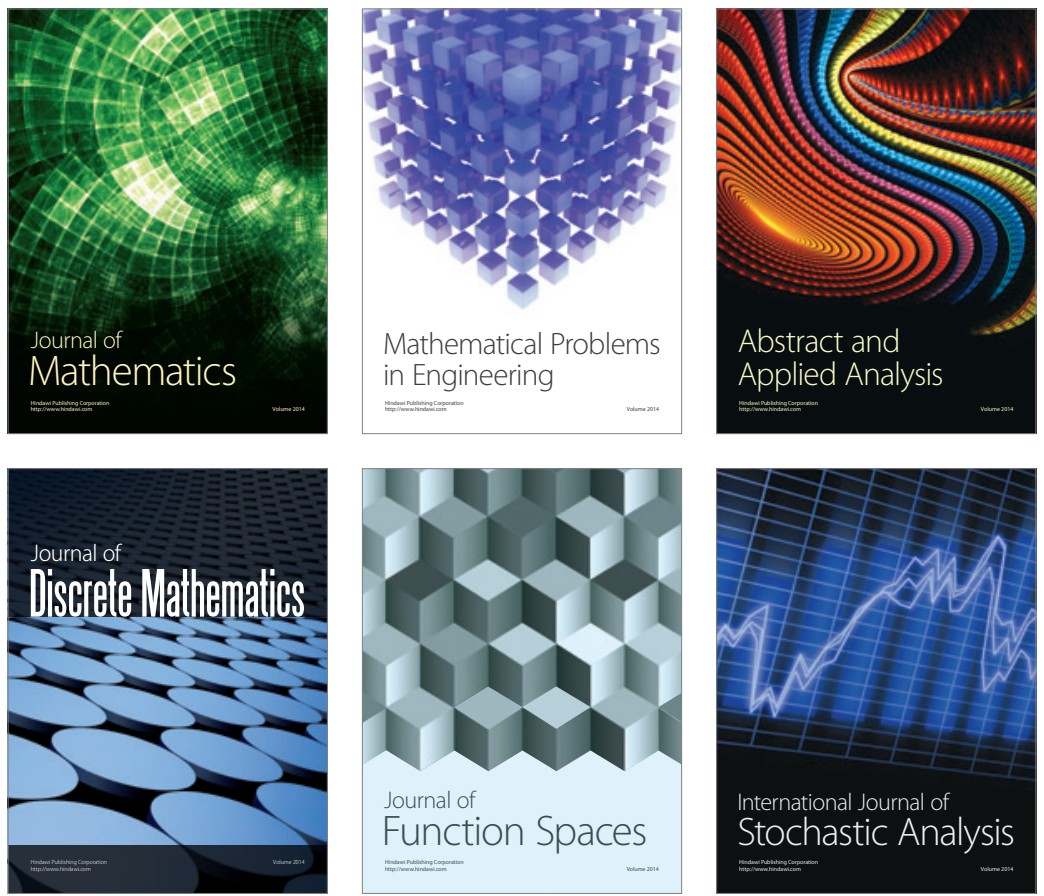

Journal of

Function Spaces

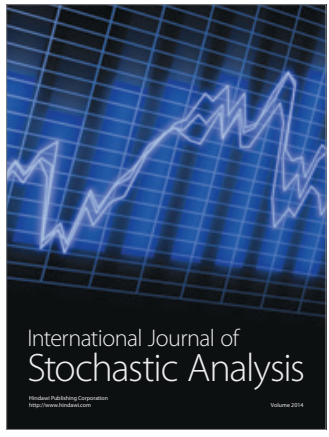

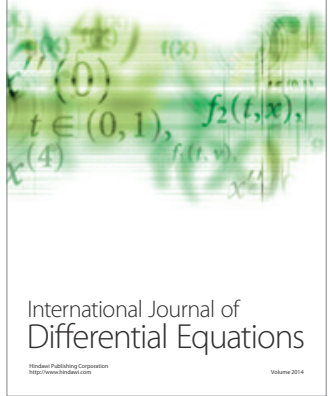
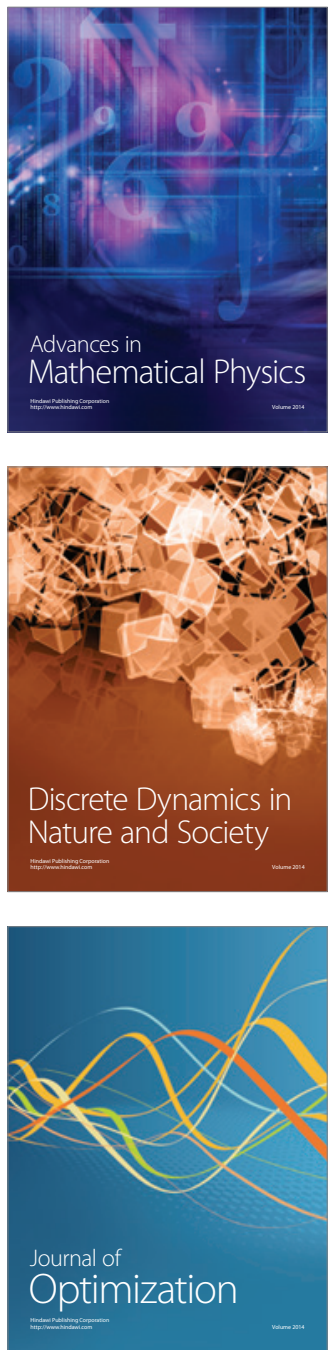